\title{
Investigation on Common Injury of Athletes in Volleyball in Different Position
}

\author{
Huihui Du ${ }^{1, a}$ \\ ${ }^{1}$ Physical Education Department of Aba Teachers University, Wenchuan 623002, Sichuan, China \\ a370515992@qq.com
}

Keywords: Volleyball sports; cause of injury; preventive measures

\begin{abstract}
Athletes injury in sports is very common in sports, volleyball as a highly technical requirements of the competitive sports items, in the technical has its special requirements, the damage also has certain regularity. In order to find out the causes and influencing factors of common injury of different position players in volleyball. The from the human body anatomy, the view point of the structural characteristics and special load characteristics of cause analysis of volleyball sports injury mechanism, to identify the damage rules of volleyball movement, and puts forward the means and measures of volleyball sports injury prevention. In order to promote the teaching and training of Volleyball in order to promote the improvement of volleyball technology and prevent the occurrence of sports injury and so on to provide useful help.
\end{abstract}

\section{Introduction}

The most prominent characteristic of volleyball is confrontation, which is characterized by collective, changeable, intense, comprehensive and so on. [1]. Volleyball is a game of great intensity, the game time is relatively long, the physical requirements of the relatively high. Reflected in the daily training and competition is particularly evident, but training is basis for the game, in the volleyball game and training, players use a variety of running, jumping, emergency stop, turned around and fell on the ground movement and opponent launched fierce competition is bound to be in motion appear sports injury. And combined with the current volleyball competition is becoming increasingly fierce, in order to improve athletic performance, strengthen strength of the Internet, players jumping height is increasing continuously; as close to the ball, athletes move faster and faster; maximum improve smashing speed, players swing speed is becoming faster. Therefore, the injury rate of athletes' organs is higher, which is an important reason to influence the training effect and competition performance. If in the teaching and training, not to strengthen the prevention of injury, it is easy to produce all kinds of damage. Especially in a quick bounce, high speed mobile, vigorously serving and spiking, easily lead to knee, shoulder peak glide capsule, the rotator cuff tendons of the waist and abdomen injury. If processing is undeserved or cure of incur loss through delay will cause muscle atrophy and chronic shoulder pain, and the emergence of dysfunction, and with the volleyball technology of continuous improvement and innovation, the damage probability is also more and more high, which to varying degrees of affects the athletes, training and physical fitness, thus to promote the sport of volleyball produce adverse effects.

\section{Object and method of study}

The object of study. Based on the Physical Education Department of Chengdu Sport University 2013, 2014 grade volleyball students as the main object of study (see Table 1), to analyze the frequently injured parts and the cause of injury, thus put forward the corresponding preventive measures and solutions, in order to better promote the volleyball sports teaching and training. 
Table 1 . basic situation of survey objects

\begin{tabular}{lll}
\hline Field position & Average age (years) & Average height $(\mathrm{cm})$ \\
\hline The first attacker & 22 & 190 \\
The second attack & 21 & 187 \\
Setter & 23 & 182 \\
\hline
\end{tabular}

Research methods. First of Chengdu Institute of Physical Education Department of sports medicine experts and scholars visit, followed by CNKI, VIP Chinese science and technology periodical network and search engine to search, and research status of volleyball sports injury is a common understanding, established the own standpoint and research focus. Then according to the research focused on the design of the questionnaire, the study of uniform distribution of questionnaires, sent 42 questionnaires, 41 copies, of which 40 valid questionnaires, the effective rate of $97.5 \%$. Finally, using SPSS17.0 software package for statistical analysis of the data obtained from the questionnaire, from which to seek mutual relations and contradictions, as the basis for the analysis of the final description.

\section{Investigation on common injury position of Volleyball Players}

After the questionnaire investigation and analysis of the 2014 and 2013 volleyball special students in the Department of physical education of Chengdu Sport University, the common sports injuries of volleyball players (see Table 2) are obtained.

Table 2 .Prevalence rate of common lesion in the investigation object

\begin{tabular}{lccccc}
\hline $\begin{array}{l}\text { Injured } \\
\text { area }\end{array}$ & $\begin{array}{l}\text { The first } \\
\text { attacker } \\
\text { (person time) }\end{array}$ & $\begin{array}{l}\text { The second } \\
\text { attack } \\
\text { (person time) }\end{array}$ & $\begin{array}{l}\text { Setter } \\
\text { (person time) }\end{array}$ & $\begin{array}{l}\text { Total } \\
\text { (person time) }\end{array}$ & $\begin{array}{l}\text { The } \\
\text { percentage of }\end{array}$ \\
\hline Knee & 17 & 6 & 5 & 28 & $23.14 \%$ \\
Shoulder & 14 & 4 & 2 & 20 & $16.52 \%$ \\
Elbow & 3 & 9 & 3 & 15 & $12.39 \%$ \\
finger & 5 & 13 & 4 & 22 & $18.18 \%$ \\
Back & 12 & 5 & 2 & 19 & $15.70 \%$ \\
ankle & 4 & 11 & 2 & 17 & $14.04 \%$ \\
Total & 55 & 48 & 18 & 121 & \\
$\begin{array}{l}\text { Percentag } \\
\text { e of }\end{array}$ & $45.45 \%$ & $39.67 \%$ & $14.87 \%$ & & \\
\hline
\end{tabular}

\section{The results and analysis}

Analysis of the causes of common injury in the main members of the team. The main players responsible for the team's main task, in difficult circumstances forced to break each other's collective block. The players mainly in the middle and long nets, back and adjust the ball attack, serving more than using the jump service technology. So, the main players knee injury was the highest, accounting for the proportion of $23.14 \%$ [damage in table 2]. Through the consulting medical experts that is mainly because in Volleyball squat action more, the movement of the knee joint mainly depends on maintaining quadriceps and patellar, and in this state, the stability of the knee joint also rely mainly on patella to maintain, resulting in patellar cartilage surface to withstand the pressure larger, longer, destruction of elastic cartilage, affected the patellar cartilage surface absorption of nutrients, prone to degeneration of cartilage. In addition to the main players in spiking, when the ball in the sky is not reasonable, the main hand to in the direction to adjust the air take-off, resulting in knee torsional force or landing when lose the center of gravity, and standing on one foot, can create a meniscus injury of the knee, patella strain, tibial bone membrane arthritis, knee medial collateral ligament injury.

The main shoulder joint injury ranked second, accounting for the injury rate 16.52\%[see Table 2], the reason is to avoid blocking force shoulder turn altering spiking line; hitting action is not standardized, to shoulder the force spiking, rather than abdominal force drive the arm moves into the whipped; excessive pursuit of improving the hitting point beyond the normal range of arm, shoulder injury, biceps brachii, head long muscle damage caused by. From the feature of human body anatomy 
analysis, the shoulder joint belongs to "hemisphere glenoid fossa", had poor stability and fighting force, prone to dislocation phenomenon, shoulder tendinitis and inflammation. This is mainly because the characteristics caused by spiking when higher than shoulder elbow.

Analysis of the causes of common injury in the second attack of the team. Blocker to block based, and most cases are moving block, so the impact of a height, and mobile hand type is not correct, hastily hand blocking caused by finger injury rate is the highest, the middle finger, little finger fracture most, the index finger contusion, accounting for damage than $18.18 \%[$ Table 2]. This is because the finger joints in addition to the thumb and wrist palm joint, the remaining 4 wrist joint capsule in a joint capsule, a smaller range of activities. When the finger by external force, the magnitude of the extension of the fingers is too large, easy to cause the interphalangeal joint and metacarpophalangeal joint dislocation, ligaments and articular cartilage injury and so on. And in the volleyball movement, use your fingers to complete the technical movement more and role larger, such as: jump serve, pass, spiking and blocking, are inseparable from the finger movements. If the above mentioned technical action is not accurate enough, it is easy to cause damage. As in the pass, spiking, due to poor technique, hand type is not correct, the fingers caused by contusion.

Secondly font deputy team ankle injury ranked second, accounted for the injury rate $14.04 \%$ [see Table 2], on the one hand is because of an ankle joint, short in medial malleolus and lateral length, varus muscle group strength than evertor group strength of large, the ligament of the lateral malleolus is weak. All blocker in blocking flutter jump the players feet step, block second judgment is wrong, before take-off crossed the midline, hitting each other players feet, are easy to create acute injury of ankle joint.

Font players elbow joint injury ranked the third. The reason is that stopped the main powerful dunks the ball will cause elbow anti earthquake wounded, font to play fast is to small arm wrist force, play for the short-term tricky, elbow reverse line formation damage. Knee injury most is the left side of the knee, the reason is long-term single leg force caused by soft knee, patella and patellar tendon periodontitis font single foot jump attack. Font of the waist and shoulder injury rate is low, the reason is less storm font, the offense is mainly to small arm wrist rapid force, attacking small amplitude, caused by shoulder injury rate low.

A common cause of injury of the setter. Setter knee injury rate highest. The reason is that in addition to block jump, to increase the pass hidden and improve offensive rhythm, setter in most cases use jump pass, transmit the net punching, setter jump when the focus of instability, twisting jump caused by knee injuries; when collusion is receiving in place, unable to make a reasonable pace, resulting in sprain of the knee joint; low center of gravity passing, defense fell diving is caused by injury. Setter refers to the joint, the elbow joint injury rate ranked second and third. The reason is that the setter blocking the main players of high storm, the thugs out of bounds is causing injury is the main reason for the. Waist, ankle injury rate is low, the reason is less offensive setter, dash jump less, the two parts of low damage ratio, waist injury is mainly incorrect defense fell diving caused.

\section{According to the characteristics of volleyball injury, the effective preventive measures are put forward}

To strengthen the safety education nip in the bud. We should put safety education into the primary task of volleyball teaching, strengthen students' awareness of prevention training, let students understand sports injury mechanism and harm, in thought really aware of prevent sports injury is to improve the important guarantee of the volleyball technical and tactical level. To prevent sports injury ideas to run through the whole teaching process, to enable students to master the scientific prevention methods and measures of sports injury to accomplish a nip in the bud, makes in Volleyball Teaching in the maximum to avoid sports injury occurs.

Strengthen the special physical quality training. To prevent sports injuries, to carry out special physical fitness training is very necessary. Volleyball special physical quality including strength, speed, endurance, flexibility, agility and bounce, in athletes mainly for jumping ability, reaction speed, starting speed, swing arm strength, finger and wrist strength, flexible ability, jumping 
movement endurance and flexibility etc.. The development of special physical quality is based on the development of general physical quality. Characteristics to consider the students in physical training, general training and special training organically combine comprehensively and effectively develop the students' physical fitness, in order to achieve the prevention of sports injury, improve the teaching effects of volleyball.

Master the correct way to protect yourself. Volleyball in both main hand or blocker usually training to by strengthening the femoral quadriceps muscle strength to reduce the relative loading of the knee joint, so as to protect the knee joint. In strengthening the speed of training, to strengthen the four shares of the two muscle and thigh special training to prevent strain. Strengthen the lumbar muscle strength exercise, enhance the muscle strength of ligament. To arrange a reasonable amount of exercise, avoid exercise in the waist fatigue cases difficult movements. Waist injury should be treated in a timely manner, and after a complete cure in order to participate in strenuous exercise. Refers to the joint injury prevention to grasp the correct technical movements in the pass, spiking and blocking, and wear a finger guard protection, usually to strengthen finger strength training and enhancement of hand muscle strength and metacarpophalangeal and interphalangeal joint flexibility and stability; before the training, the competition do hand of preparing activities to effectively prevent and reduce the occurrence of injury of finger.

Scientific arrangement of teaching training and competition. In teaching, training and competition according to the age of the athletes, health conditions and technical level to arrange training, reasonable arrangement of the amount of exercise, in particular, to avoid excessive burden on the part of the exercise organ. To strengthen the teaching of basic skills, so that players can better grasp the correct technical movement essentials, the arrangement of the training content, it is necessary to avoid the "singles" training mode. In the learning of new actions, from simple to complex, from easy to difficult, step by step. To strengthen the comprehensive physical training, improve the overall physical quality, such as: strength, balance, endurance, flexibility, explosive force, etc..

\section{Summary}

Through the investigation and study found; volleyball sports injury is a very high probability and players in different positions at the site of the injury is present certain regularity. Through the analysis, it is known that cause these sites of injury in both objective factors of the structural weaknesses of human anatomy and volleyball technical and tactical characteristics caused by. So I hope through this demonstration on volleyball injury, later in volleyball training and competition in the coaches and athletes pay more attention to prevention and protection of these sites, and combined with the effective preventive measures, in order to promote volleyball can be more healthy and harmonious development.

\section{References}

[1] Huang Hansheng. Volleyball [M]. Beijing: People's education press, 2006.136-139

[2] Gaorun flowers. Volleyball training and sports injuries [J]. Chinese volleyball, 2002,20 (10): 23-25

[3] He Shaojun. The biochemical mechanism and recovery process of exercise induced fatigue [M]. Beijing: Higher Education Press, 2001.196-198

[4] tension for. Sports psychology [M]. Beijing: Higher Education Press, 2007.260-262

[5] Liu Yanping. Analysis of sports fatigue and its mechanism [J]. Journal of Xi'an Physical Education University, 2001,15 (3): 1 